\title{
RIJEČ UNAPRIJED
}

\section{Drago Roksandić i Ivana Cvijović Javorina}

II a prvi pogled, dva opsežna sveska knjige Hotimično iskustvo: diskurzivna proza Vladana Desnice - koji sadržavaju sve piščeve objavljene eseje, studije i rasprave, zatim prikaze, ocjene i kritike, polemike te intervjue i razgovore, a na kraju i rukopise iz njegove neobjavljene ostavštine - ničim ne opravdavaju temu splitskih Desničinih susreta 2014. Vladan Desnica i Split (1920. - 1945.). ${ }^{1}$ Pažljivu čitatelju neće biti teško uočiti da je pisac u svojim kasnijim godinama, nakon odlaska iz Splita, rijetko kada spominjao iskustva iz grada svoje mladosti. Ako je to i činio, u pravilu se ograničavao na što, izbjegavajući gdje. Nasuprot tome, Marinkovićeva „Biografija Vladana Desnice“, objavljena u drugom svesku spomenutog izdanja, uputila je Pripremni odbor Desničnih susreta 2014. na pretpostavku da su upravo splitske godine - uključujući šibenska, zagrebačka i pariška intermezza u periodu od 1921. do 1930. - ključne za razumijevanje Desničina stvaralačkog sazrijevanja. ${ }^{2}$

Tome su prvorazredno svjedočanstvo i sjećanja Vladimira Rismonda, Desničina prijatelja iz tih godina. ${ }^{3}$ Rismondo nije bio jedini s kojim je Desnica u Splitu bio blizak upravo zbog umjetničkih afiniteta i koji bi vjerojatno mogao slično svjedočiti. U Desničinoj ostavštini više je pisama intoniranih poput pisma slikara Vjekoslava Paraća iz Pariza 17. travnja 1930.:

Dragi Desnica! Koliko li sam se samo puta sjetio na Vas i nikad da Vam se javim. No što ćete to Vam je moja mana ili komodnost, lijenost ili već kako hoćete. No Boga mi koji put čisto ko da mi falite. Onda na primjer kada prolazim i razgledam koji muzej, pa kad mi se pred nosom isprči trbušasta cukarijera ili kad vidim koji osobiti stolac Louis XV ili XVI onaj s krivim i onaj s aretim nogama onda "nema Boga“ da se nesjetim na Vas. Kad je sumorno vrijeme a iza lumparije onda naravna stvar da je pravi štimung da se ide po antiquariatima, tada mi osobito falite. Ajde izmislite nešto pa se dogovarajte ovamo. Karneval je doduše prošao, ali zato sada počinje proljeće i hiljade šarenih tankih opravica čeka da samo malo bolje zagrije pa da izlete na boulevarde. $(. . .)^{4}$

Prijateljska intonacija, uvažavanje Desničine kultiviranosti i izobraženosti, ali i spontanosti dolaze na takav način do izražaja i u porukama osoba starijih od Vjekoslava Paraća, rođenog 1904. Najveće povjerenje mu je tada bio iskazivao skladatelj Ivo Parać, rođen 1890. godine:

1 Vladan Desnica, Hotimično iskustvo: diskurzivna proza Vladana Desnice (prir. Dušan Marinković), 2 sv., Zagreb 2005. - 2006.

2 Isto, Knjiga druga, 223-231.

3 Vladimir Rismondo, „Poezija Vladana Desnice“, „Književni profil Vladana Desnice“, „Sjećanje na Vladana Desnicu“ i „Vladan Desnica“, u: Isti, Oblici i slova, Split 1979., 133-136, 179-183, 210-213 i 214-220.

4 Vjekoslav Parać - Vladanu Desnici, Pariz, 17. travnja 1930., Osobna ostavština Vladana Desnice. 
Dragi Vladane, (p)rimio sam Vaše cijenjeno pismo, i jedva da Vam odgovaram ... Strašno sam neraspoložen i nemam baš volje za ništa, pa tako ni za pisanje. Nego nestrpljivo čekam da stignete u Splitu, pa da me po malo razgalite dušu i da mi rastjerate tumornu maglu što okolo mene vije. - Zahvaljujem Vam na prijateljske podstreke e da čim prije dovršim Bijednu Maru, ali zamislite si Vi u kakvom se ja nalazim duševnom stanju, koji nimalo ide u korist jednog takvog proćućenog estetskog posla. Vi znate da kad ja započnem jednu stvar, u brzo je vodim do konca: tako se nadam i vjerujem u pogledu instrumentacije ove opere, okolo čega već nekako radim, ali nimalo kako bi baš trebalo. Imam mnoge i mnoge stvari da Vam pričam, ali nipošto pismeno: govoriti ćemo kad se Vi vratite u Splitu, a to želim da čim prije bude. Pozdravite mi sve prijatelje i doviđenja Vaš Ivo Parać. ${ }^{5}$

S Ivom Paraćem u vezi bio je i Desničin skromni ulazak u kulturnu javnost. U Splitu je izgleda prvi put medijski bio registriran u Novom dobu 1932. godine kao sporedni lik u bilješci preuzetoj iz beogradskog tiska „O Paraćevoj 'Bijednoj Mari'“:

Beogradsko „Vreme“ donosi sliku našeg sugrađanina M[aestr]a Iva Paraća, a uza nju jedan prikaz njegove opere „Bijedna Mare“ koju je u posljednje vrijeme baš dovršio za teatar. U prikazu su donesene neke općenite informacije u Paraću, pa se zatim govori o libretu, koji je, prema Luki Botiću, iskonstruisao sam kompozitor, a pomagao mu je pri pisanju g. Vladan Desnica. ${ }^{6}$

Istim beogradsko-splitskim redoslijedom pojavio se i svojim prvim autorskim radom „Izložba vajara Dujma Penića u Splitu“, objavljenim u Beogradu 1933. godine, u Desničinoj dvadeset i osmoj godini, a potom u splitskom Novom dobu. ${ }^{7}$ Važno je da se tom prilikom u javnosti oglasio kao čovjek od prepoznatljiva umjetničkog ukusa s jasnim odmakom od Meštrovićevih kanona, a s formulacijama koje anticipiraju „zrelog“ Desnicu:

U Penićevim odlikama: u euritmiji života, skladnosti i harmoničnosti koncepcija i staloženosti izraza, u njegovu stavu prema pojavama i otkrovenjima života, stavu koji nije violentna reakcija unezverenog primitivca nego osjećajem protkana, sređena kontemplativnost, u tom mirnom i dubokom sisanju sokova života i u tom mirnom ali širokom zahvatu svih ljudskih elementarnih sadržaja i emocija, mi gledamo blagodat jednog kulturnog naslijeđa koje - više nego što bi se naslijeđivalo po krvi - živi u duhovnoj atmosferi i u kulturnoj tradiciji, a kojoj je najjasniji znamen instinktivna, prirođena familijarnost sa višim stepenima razvoja čovječjeg duha i umjetničkog izražavanja. ${ }^{8}$

Pišući o Peniću, Desnica kao da piše ono što će dvadesetak godina kasnije kritičari pisati o njemu samom. Sve je implicirano u Desničinoj kritici - uključujući mediteranizam i njegovu aproprijaciju Crocea!

Za takva Vladana Desnicu, kao ni za većinu drugih njemu sličnih nazora, nije tada u splitskoj javnosti bilo previše afiniteta. Splitski kulturni main-stream, neovisno o političkim orijentacijama, nije mario ni za mediteranizam ni za Crocea. Za Vladana Desnicu još i ma-

5 Ivo Parać - Vladanu Desnici, Split, 10. prosinca 1931., Osobna ostavština Vladana Desnice.

6 Novo doba (Split), br. 93, 21. 4. 1932., 4. Beogradski i splitski novinski début sigurno nije ushitio Desnicu jer je suradnja s Ivom Paraćem bila mnogo složenije naravi. Vidjeti: V. Desnica, Hotimično iskustvo. Knjiga druga, 225.

7 Život i rad, god. VI, knj. 17, sv. 99, Beograd 1933., 1211-1213 (ćir.). Isti tekst, ali pod naslovom „Kipar Dujam Penić. (Prigodom izložbe u Splitu)“ objavljen je u splitskom Novom dobu, br. 241, 14. 10. 1933., 9.

8 V. Desnica, Hotimično iskustvo. Knjiga prva, 337. 
nje jer je bio sin dr. Uroša Desnice, desetljećima već javno vrlo eksponiranog u Dalmaciji i sučeljenog na raznim frontama u raznim situacijama. ${ }^{9}$ Iako je dr. Uroš Desnica svoj politički zenit bio doživio upravo u Splitu 1920./1921. godine, kao jedan od ključnih dužnosnika u Pokrajinskoj vladi za Dalmaciji, definitivno se doselio u ovaj grad tek 1927. godine, kada je i svoj odvjetnički ured prenio iz Obrovca u Split. O tome je obavijestio splitsku javnost u Novom dobu: „Odvjetnik Dr. Uroš Desnica otvorio je kancelariju u Splitu Sinjska ulica 7 II. kat (kuća Brainović, povrh Trgovačke Komore). ${ }^{\text {"10 }}$

Njegov sin Vladan bio je tada student prava u Zagrebu i spremao se u Pariz zbog motivacija koje su, čini se, najmanje bile pravničke naravi:

Akademske 1927/28. odlučio je da studira dva semestra pravo i filozofiju u Parizu, ali je ponajviše „slušao tečajeve povijesti i teorije umjetnosti“, radeći na svome muzikološkom, historijskom i likovnom obrazovanju, nego što je pohađao predavanja iz prava. Po brojnim sačuvanim afišama i programima s muzičkih koncerata i slikarskih izložbi vidi se koliko je participirao u kulturnoj ponudi u Parizu. ${ }^{11}$

Nije bio jedini Splićanin sličnih motivacija u Parizu u to doba. Naprotiv. Pored Vjekoslava Paraća tamo su tada bili i Dujam Penić, Andro Vid Mihičić i Juraj Plančić, ali i Bogdan Radica te više drugih koji nisu bili Splićani, ali su ih slični afiniteti mogli povezivati, poput, primjerice, Sergija Glumca.

Međutim, Desnica je svoju budućnost vidio u Splitu. On i mnogi drugi u to su se doba doseljavali u Split kao u grad koji ima „budućnost“, kao što su u skoro desetljetnom rasponu zabilježili i Marko Car i Tin Ujević. Za Cara,

Split je u ovom trenutku varoš koja živi mahom u budućnosti. U teoriji, i kao po nekom aktu samoodredjenja, on je sebi namenio ulogu trećeg kulturnog i ekonomskog centra u sklopu nove države. Posle Beograda i Zagreba - veli se ovde - ima da dodje odmah Split. I to će morati neminovno biti, čim se oko njega pomnože prilazna i saobraćajna sredstva, čim se u njegovu luku slije širi i bujniji mlaz ekonomskog života. Za sad je ovde taj život, a naročito trgovački promet zbog političke situacije na Jadranu, još suviše mlitav da bi mogao da da impresiju jačeg pokreta i intenzivnijeg rada. Jedino fijuk lokomotive na željezničkoj stanici, koji s vremena na vreme propišti vazduhom, deluje na putnika kao neki predznak lepših dana, kao neka fanfara budućnosti. ${ }^{12}$

Pišući usred velike svjetske krize, 1930. godine, Tin Ujević bio je skoro na granici splitske urbane euforije:

Split je i ranije, premda nije bio glavni grad Dalmacije, bio najveći po svojoj luci i središnjem položaju; svoj novi porast duguje on seljenju zadarskoga činovništva i ličkoj željeznici iz 1925. koja je, dižući prometne veze, privukla radnu snagu iz okoline. Već od 1925. mogao je putnik da običnim okom primijeti širenje grada prema periferiji, dok je u isti mah konstatirao kako se lijepo diže u mjestu blagostanje i luksuz. Split, koji je sada postao sijelo

9 Dovoljno je pogledati koliko ga i gdje sve registriraju digitalni pretraživači Novog doba i Jadranskog dnevnika u Sveučilišnoj knjižnici u Splitu (http://dalmatica.svkst.hr/?sitetext=315).

10 Novo doba (Split), br. 217, 17. 9. 1927., 6.

11 V. Desnica, Hotimično iskustvo. Knjiga druga, 224.

12 Marko CAR, „Utisci iz Splita“, Novo doba (Split), br. 182, 12. 8. 1922., 2-3. 
banovine, vjeruje u još veći napredak ako se ostvare nove željezničke mreže. I može se mirne duše reći: na prekrasnom suncu prvih januarskih dana ove 1930. osjeća se, na šetnji pod paomama na obali, jedan talas novoga života. Ova luka živi, pa ako i nije Madrid, kao da će da bude jedna jadranska Barcelona. ${ }^{13}$

Dakle, cilj je Desničinih susreta 2014.: Vladan Desnica i Split (1920. - 1945.) bio, s jedne strane, istražiti, kritički propitati i raspraviti otvorena pitanja u vezi s obiteljskim, profesionalnim (pravničkim) i, nadasve, generacijskim umjetničkim sazrijevanjem Vladana Desnice u Splitu, a potom i pitanja u vezi s časopisom Magazin Sjeverne Dalmacije te Desničinim shvaćanjima umjetničkog stvaralaštva i političkog angažmana u njegovim splitskim godinama. S druge strane, cilj je bio raspraviti otvorena pitanja u vezi s kulturnom, društvenom i političkom situacijom Splita u kojoj je Desnica odrastao i sazrio kao stvaralac. I sâm je nekoliko puta napomenuo da je na Proljećima Ivana Galeba počeo raditi u Splitu kasnih 1930-ih pa čak i da je sve najvažnije - što je kao pisac naučio - naučio u Splitu. Na taj način Desničini susreti 2014. predstavljaju bitan iskorak u proučavanju obiteljske prošlosti Vladana Desnice, njegova formativnog razdoblja, ali i međuratne povijesti grada Splita, kojoj se u posljednje vrijeme posvećuje sve više istraživačke pozornosti. Koliko se u tome uspjelo, velikim dijelom bi trebao pokazati ovaj svezak Biblioteke Desničini susreti.

Zbornik znanstvenih radova Vladan Desnica i Split (1920. - 1945.) sadržava članke koji su nastali na temelju priopćenja s Desničinih susreta 2014., održanih u Splitu 19. i 20. rujna te u Islamu Grčkom 21. rujna 2014. godine. ${ }^{14}$ Potpisani urednici osjećaju potrebu naglasiti da su za uspješan rad skupa, bitnu pretpostavku za nastanak ovog zbornika, zaslužni kolege s Filozofskog fakulteta Sveučilišta u Splitu, a naročito prof. dr. sc. Aleksandar Jakir, dekan Filozofskog fakulteta, koji je i sam bio sudionik skupa. Sedamnaest od devetnaest sudionika preradilo je svoja priopćenja u članke. Njihovi su radovi prije svega svjedočanstva vlastitih istraživanja, ali oni zrcale i učinke nerijetko pasionirane pa i vrlo polemične rasprave na samom skupu. Najviše se raspravljalo, dakako, o Vladanu i dr. Urošu Desnici, potom o drugim, najčešće znamenitim Splićanima tog doba, ali i o splitskim pučanima te o tadašnjoj velikoj urbanoj transformaciji Splita, licu i naličju kulturnih i umjetničkih inovacija trajne vrijednosti, koje su i bile u središtu pozornosti.

Pripremajući skup, članovi Pripremnog odbora bili su pošli od pretpostavke da je bolje fokusirati se na Vladana Desnicu u Splitu nego na Split u godinama kada je u njemu Desnica živio ili kada je za njega bio na različite načine vezan. Međutim, upravo zbog svoje kvalitete, skup je otkrio da su i Vladan Desnica i Split u tim godinama istraživački i dalje velike nepoznanice, koliko god bile respektabilne bibliografije radova i u jednom i u drugom pogledu.

Splitske godine Vladana Desnice bile su godine njegova sazrijevanja, ali i godine velikoga urbanog uspona Splita. Ostavši bez Pule, Rijeke i Zadra, Kraljevina SHS/Jugoslavija u međuratnom razdoblju u svojim granicama nije imala većeg grada od Splita na jadranskoj

13 Tin Ujević, „Splitski vidici. Četrdeset i prva hiljada Splićana“, Putopisi, Zagreb 2001., 148.

14 Vidi: Drago Roksandić - Filip Šimetin Šmgvić - Nikolina Šimetin Š́egvić (ur.), Desničini susreti 2014 . Vladan Desnica i Split 1920. - 1945. Program rada / sažeci izlaganja, Zagreb 2014. Programska knjižica dostupna je i na internetskoj stranici Desničinih susreta (http://kula-jankovica.unizg.hr/files/file/ds-pk-2014.pdf). 

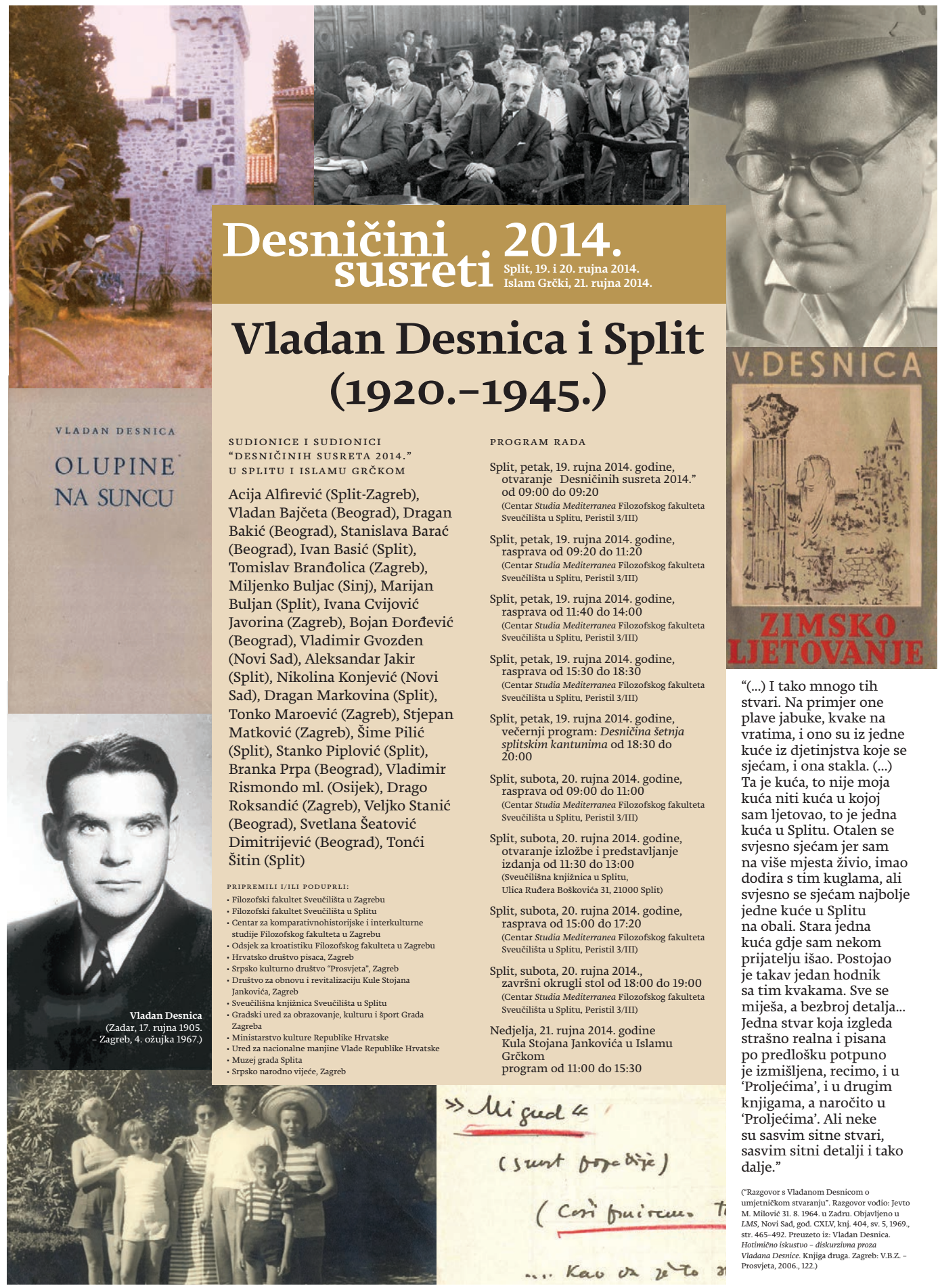

(Split), Nikolina Konjević (Novi Sad), Dragan Markovina (Split),

Tonko Maroević (Zagreb), Stjepan Matković (Zagreb), Šme Pilić

(Split), Stanko Piplović (Split), Branka Prpa (Beograd), Vladimir Rismondo ml. (Osijek), Drago Roksandić (Zagreb), Veljko Stanić (Beograd), Svetlana Šeatović Dimitrijević (Beograd), Tonći Sitin (Split)

ozofski fakultet Sveučilišta u Splitı

.

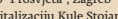
Jank Gradski ured za obrazovanje, kulturu i šport Grad

.

\section{$\gg$ Migud 4}

\section{(sunt orgadije) \\ (Corifuiras.}

... Kav or zeto $x$
“(...) I tako mnogo tih stvari. Na primjer one plave jabuke, kvake na vratima, i ono su iz jedne kuće iz djetinjstva koje se sjećam, i ona stakla. (...) Ta je kuća, to nije moja kuća niti kuća u kojo sam ljetovao, to je jedna kuća u Splitu. Otalen se svjesno sjećam jer sam na više mjesta živio, imao dodira s tim kuglama, ali svjesno se sjećam najbolje jedne kuće u Splitu na obali. Stara jedna kuća gdje sam nekom prijatelju išao. Postojao je takav jedan hodnik sa tim kvakama. Sve se miješa, a bezbroj detalja..

Jedna stvar koja izgleda strašno realna i pisana po predlošku potpuno je izmišljena, recimo, i u 'Proljećima', i u drugim knjigama, a naročito u 'Proljećima'. Ali neke su sasvim sitne stvari, sasvim sitni detalji i tako dalje."

("Razgovor s Vladanom Desnicom o

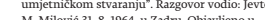
LMS, Novi Sad, god. CXIV, knj 404 , sv 5,1969

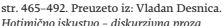
Vladana Desnice. Knjiga druga. Zagreb: V.B.Z. Prosvieta, 2006., 122.) 
obali. S druge strane, u prijelomnim danima između ratnog primirja 1918. godine i Rapalskog ugovora 1920. godine, od studenog do studenog, Splićani su velikom većinom, kao rijetko tko drugi u Državi Slovenaca, Hrvata i Srba/Kraljevini Srba, Hrvata i Slovenaca, iskazivali svoje jugoslavensko opredjeljenje. Time je i njihov urbani imaginarij, kako politički tako i kulturni, startno bio distinktivan i u Hrvatskoj, a dakako i u Jugoslaviji. Koliko god to opredjeljenje bilo uvjetovano otporom odredbama Londonskog ugovora, imalo je nesumnjivo i svoje dublje korijene u hrvatskoj povijesti 19. stoljeća, napose u iskustvu „novog kursa“ u godinama uoči Prvoga svjetskog rata.

$S$ druge strane, ono nije bilo apologetsko spram etabliranog poretka jer je političko raslojavanje u gradu bilo vrlo veliko i mijenjalo se iz godine u godinu između 1918. i 1941. U vrijeme stvaranja Banovine Hrvatske politička diferencijacija, s praktično hegemonijskim statusom Hrvatske seljačke stranke, bila je stubokom različita nego 1918. godine. Njezina politička kvaliteta još jedanput se promijenila u uvjetima okupacije i kolaboracije 1941. godine, tako da je u rujnu 1943. godine, nakon kapitulacije fašističke Italije, Narodnooslobodilački pokret rijetko gdje u Hrvatskoj i Jugoslaviji bio utjecajan kao u Splitu.

Desničini susreti 2014. završili su s pitanjima koja su definirala raspravnu agendu Desnicinih susreta 2015. s prividno inverznom temom Split i Vladan Desnica (1918. - 1945.): umjetničko stvaralaštvo između kulture i politike. Time je limitiran okvir ovog predgovora jer će se s objavljivanjem sljedećeg zbornika, posvećenog najavljenoj temi, otvoriti pitanje pogovora koji bi trebao sumirati temeljne spoznaje oba sveska i time, nadajmo se, otvoriti putove daljnjih razvojnih mogućnosti Programa znanstvenih rasprava „Desničini susreti“.

Kao urednici ovog zbornika, dužni smo prije svega zahvaliti autorima, ali i recenzentima, čija su imena otisnuta u knjizi. Svaki članak pojedinačno recenziralo je dvoje recenzenta. Budući da u zborniku prevladavaju historiografski radovi, među recenzentima ima najviše povjesničara. Posebno zahvaljujemo prof. dr. sc. Zvonku Kovaču s Filozofskog fakulteta Sveučilišta u Zagrebu i prof. dr. sc. Borisu Škvorcu s Filozofskog fakulteta Sveučilišta u Splitu, koji su recenzirali zbornik kao cjelinu. Srdačnu zahvalnost dugujemo dekanu Filozofskog fakulteta Sveučilišta u Zagrebu prof. dr. sc. Vlatku Previšiću na podršci bez koje ne bi bilo moguće u kratkom roku osigurati potrebna financijska sredstva za njegovo objavljivanje. Zahvalnost dugujemo i prof. dr. sc. Aleksandru Jakiru, čijim zalaganjem ovaj zbornik izlazi i kao izdanje Filozofskog fakulteta Sveučilišta u Splitu, što je nesumnjivo veliko priznanje za Biblioteku „Desničini susreti“.

Zbornik je slikovno obogaćen manjim dijelom zahvaljujući autorima, a većim susretljivosti i povjerenju obitelji Desnica, Muzeja grada Splita i Sveučilišne knjižnice u Splitu. Iskreno im zahvaljujemo, posebno dr. sc. Urošu Desnici, mr. sc. Petru Kroli, Goranu Borčiću i Branku Braliću.

Na kraju, kao i više puta do sada, odlična suradnja s kolegama iz FF-pressa Filozofskog fakulteta Sveučilišta u Zagrebu, posebno s Borisom Buiem i Markom Marakovićem, omogućila je da se ovaj zbornik pojavi u javnosti nakladnički kvalitetniji nego prethodni.

Zagreb, 22. srpnja 2015. 